\title{
Novas evidências sobre poupança, investimento e crescimento na América Latina
}

\author{
Gilson Geraldino Silva-Jr* \\ Raimundo Nascimento Felix**
}

Resumo:Este artigo trás novas evidências sobre a relação entre poupança e crescimento e poupança e investimento a partir de um painel balanceado com informações anuais de 18 países latino americanos entre 1980 e 2009 construído com informações da base de dados do Banco Mundial. Usamos os testes de raízes unitárias para dados de painel de Levin, Lin e Chu (2002) e de Im, Peasaran e Shin (2003) para checar as pré-condições para cointegração em painel e o procedimento de Carroll e Weill (1994) para calcular os efeitos de longo prazo entre as variáveis analisadas. Não detectamos cointegração e detectamos relação de equilíbrio de longo prazo e Granger bicausalidade poupança e investimento e poupança e crescimento neste grupo de países neste período.

Palavras-Chave: Poupança. Investimento. Crescimento. América Latina.

Classificação JEL: E22; E6; F4.

\footnotetext{
*Graduação em Matemática pela Universidade Federal do Acre, mestrado e doutorado em Economia pela Universidade Católica de Brasília. Atualmente é Consultor na área de Cenários Macroeconômicos da Caixa Econômica Federal.

**Bacharel e Mestre em Economia pela UFMG, Doutor em Economia pela UFRGS. Atualmente é Pesquisador Visitante no IPEA-DF.
} 


\section{Introdução}

Este artigo analisa a relação entre poupança e crescimento e poupança e investimento na América Latina. Consideramos um painel balanceado de países com informações anuais entre 1980 e 2009 construído apartir da base de dados do Banco Mundial. As 18 nações analisadas são: Argentina, Bolívia, Brasil, Chile, Colômbia, Costa Rica, Equador, El Salvador, Guatemala, Honduras, México, Nicarágua, Panamá, Paraguai, Peru, República Dominicana, Uruguai e Venezuela.

Destacam-se aqui três momentos distintos no período analisado. Um, a década de 1980, que foi um período de estagnação econômica e de altas taxas de inflação para a totalidade dos países da América Latina - por esse motivo, foi denominada pelos pesquisadores de "década perdida". No referido período os gestores econômicos buscaram estabilidade monetária nos seus respectivos países. Outro, a década de 1990, destacamos as várias crises cambiais que afetaram a América Latina. Estas crises cambiais se originaram em países europeus (em 1992), estenderam-se para o México (em 1994), nas economias asiáticas (em 1997), na Rússia (em 1998), no Brasil (em 1999) e na Argentina (em 2001). Os efeitos das referidas crises eram notados internamente no país de origem, mas proporcionavam reflexos em outras economias. Tal realidade econômica não protagonizou o retorno da inflação a patamares superiores na região, mas influenciou na ritmo do crescimento econômico.

No terceiro momento, a partir dos anos 2001/2002, a economia internacional tem um período menos turbulento. As economias da América Latina cresceram em ritmo acelerado, seguindo a tendência global. Inaugurase uma fase em que pequenas e médias economias da América Latina e outras regiões do globo passam a receber maior volume de investimentos diretos externos impulsionando o desempenho do Produto Interno Bruto (PIB) dessas economias. Surge assim uma nova denominação para alguns países da região: os emergentes.

Em 2008/2009, o mundo enfrentou uma nova crise econômica, considerada a maior desde a de 1930. Precipitada pela falência do tradicional banco de investimento norte americano Lehman Brothers, em efeito dominó outras grandes instituições financeiras quebraram. Tal processo ficou conhecido como a "crise dos sub-primes". A diferença entre as "crises cambiais" observadas na década de 1990 e a "crise dos sub-primes" deu-se pelo fato desta última ter seu início nos EUA e se expandido pela maioria das economias mundiais.

Em suma, poupança como potencial elemento propulsor do crescimento e do investimento dos países é uma questão clássica em macroeconomia. Os fatos econômicos, muitas vezes exógenos aos países, podem ifluenciar na relação entre estas variáveis. As modernas técnicas econométricas para dados em painel permitem verificar com maior precisão a relação entre estas variáveis para grupos de países, bem como a causalidade entre elas.

A seguir revisamos a literatura e analisamos os resultados encontrados neste trabalho. 


\section{Breve revisão da literatura}

\subsection{Poupança e investimento}

Destacamos duas linhas de pesquisas voltadas para o estudo da relação entre poupança e investimento: a primeira, pertinente aos países latino-americanos, é o estudo da poupança e do investimento em uma pequena economia aberta. Na nossa amostra, todos os países são pequenas economias, podendo sua maioria ser considerada como abertas. A segunda preocupa-se com o nível de abertura das economias para a perfeita mobilidade de capital e gira em trono do suposto "enigma" de Feldstein e Horioka.

No caso das pequenas economias abertas (Smal Open Economies, SOE) Finn (1990) desenvolveu um modelo de gerações superpostas de poupança e investimento para dois países de economias abertas. Para aquela autora, uma estrutura estocástica é essencial para uma análise em profundidade quanto ao comportamento da poupança e do investimento na economia. Além disso, facilita a análise da evolução das variáveis tecnológicas e da correlação entre as séries. Tais premissas são embasadas em evidência empírica. As simulações para uma economia artificial revelaram relação significativamente positiva entre poupança e investimento.

A análise do ciclo real de negócios em uma SOE coube a Mendonza (1991). Observando a perfeita mobilidade de capital entre os países, desenvolveu e testou um modelo para a economia canadense no pós-guerra. O modelo é consistente com a observação de correlação positiva entre poupança e investimento, inclusive em um mundo com perfeita mobilidade de capital. Estes resultados estão de acordo com fatos estilizados: (i) agentes racionais ajustam consumo, poupança e investimento diante de flutuações econômicas; (ii) as flutuações são pró cíclicas no consumo, investimento e no emprego; (iii) a exibição de mais variabilidade no investimento do que o produto ou consumo.

Vale ressaltar ainda que (i) a estrutura demográfica dos países resulta em taxas de poupanças diferentes. Além disso, a razão população versus nível de emprego melhora com o decréscimo na taxa de poupança (Besanger, 2004); (ii) ao considerarmos as condições para a taxa de poupança ótima em uma SOE com recursos não renováveis, a taxa de poupança ótima dessa economia é crescente com o estoque dos recursos não renováveis e decrescente com o montante de ativos financeiros (Boyce, 2009); (iii) Mansoorian et alii (2010) estudaram o impacto da inflação na poupança, investimento, consumo e emprego em uma SOE, e concluíram que um aumento na taxa de inflação aumenta o custo dos bens de consumo em relação ao lazer. Tem-se aí duas implicações: por um lado, reduz a oferta de trabalho causando uma diminuição da produtividade marginal do capital e a queda no investimento; por outro lado, provoca uma queda substancial na poupança e, conseqüentemente, no investimento.

Feldstein e Horioka (1980) destacam duas visões entre poupança doméstica e a perfeita mobilidade de capital mundial. A primeira, foca na 
mobilidade de capital, isto é, com perfeita mobilidade mundial de capital, é pequena ou inexistente a relação entre investimento doméstico em um país e o montante de poupança ali gerado. A segunda, preocupa-se com as preferências por esta ou aquela carteira e a rigidez que causam, impedindo o fluxo de capital de longo prazo no país - o aumento na poupança doméstica refletirá preliminarmente no investimento doméstico adicional.

As evidências empíricas levaram Feldstein e Horioka (1980) a concluir que prevalece a segunda visão, uma vez que as diferenças internacionais para os países industrializados correspondem quase à igualdade entre as taxas domésticas de poupança e de investimento.

Já Levy (1995) estendeu o modelo de Feldstein (1983) com a inclusão da taxa de câmbio flexível e política fiscal endógena, mostrando que sob esta nova condição a correlação positiva entre poupança-investimento pode aumentar. Além disso, aquele autor observara que a correlação entre poupança e investimento não depende da mobilidade do capital, ou seja, o comovimento entre poupança e investimento não se dá, necessariamente, devido à mobilidade de capital imperfeita.

Mas o "enigma" de Feldstein e Horioka é mesmo um enigma? Para Levy (1998) não há surpresa em encontrar correlação positiva entre poupança e investimento. A teoria neoclássica do crescimento mostra que em estado estacionário, poupança e investimento crescerão proporcionalmente ao produto com a permanência das mesmas taxas. A correlação não depende do grau de mobilidade internacional do capital, e surpresa seria não achar correlação entre estas variáveis. Levy (1998) destaca a existência de tal conflito porque Feldstein e Horioka (1980) desconsideraram que as séries temporais de investimento e poupança são cointegradas, tanto em nível quanto em razão do Produto Interno Bruto (PIB). Em outro artigo, Levy (2000) aponta que há forte relação cíclica de longo prazo entre poupança e investimento, evidenciando ser independente, temporalmente, para o período de tempo considerado no estudo (1947-1987); verificou-se fortemente significativa também no curto prazo.

Em uma extensão do modelo de Feldstein e Horioka (1980), Gunji (2003) inclui uma variável dummy ao modelo que captura os níveis de proteção legal dos investidores domésticos. Aquele autor utilizou dados de poupança doméstica e de investimentos domésticos nos países da OCDE, no período compreendido entre 1970 e 2000, incluindo testes para subamostras. As avaliações mostraram que nos países que adotam o sistema francês de legislação, que têm proteção mais branda para investidores domésticos, as taxas de investimento doméstico geralmente é menos fortemente correlacionada com as taxas de poupança doméstica, corroborando com o "enigma de Feldstein e Horioka".

Kin (2001) utilizou dados em painel para dezenove países da Organisation for Economic Co-Operation and Development (OECD) ${ }^{1}$, no período compreendido entre 1960 a 1992. Utilizando uma extensão da metodologia de Feldstein e Horioka (1980), aquele autor constatou a existência de alta correlação

1 Alemanha, Austrália, Áustria, Bélgica, Canadá, Dinamarca, Espanha, Finlândia, França, Grécia, Irlanda, Itália, Japão, Holanda, Nova Zelândia, Portugal, Reino Unido, Suíça e EUA. 
entre as séries de poupança e de investimento para aqueles países. O teste de cointegração aplicado indicou que as séries de poupança e de investimento são cointegradas. A única exceção foi para a Áustria, onde o teste rejeitou a hipótese nula de cointegração.

Em um estudo para vinte e quatro países da $\mathrm{OECD}^{2}$, utilizando dados de 1960 a 2000, Fouquau et alii (2009) concluíram que a relação entre poupança doméstica e investimento não é linear. Três variáveis apresentaram grande influência na retenção dos coeficientes de poupança: o grau de abertura, o tamanho do país e a relação entre conta corrente e PIB. Tais coeficientes não apresentaram homogeneidade, nem disposição em classes homogêneas entre os países - o que evidencia a alta variabilidade do grau de mobilidade do capital entre esses países. O "enigma" de Feldstein e Horioka (1980) não se verificou no período entre 1960 e 2000 para a maioria dos países da amostra.

Em suma, o "enigma" Feldstein e Horioka (1980) parece ser mais uma imprecisão empírica gerada por insuficiência metodológica da época do que realmente um enígma.

\subsection{Poupança e crescimento}

Carroll e Weil (1994) examinaram empiricamente a relação entre poupança e crescimento da renda utilizando dados agregados para um grupo de países no período 1958 a 1987. Eram 64 países de uma amostra bastante heterogênea - incluindo países desenvolvidos, países em desenvolvimento, países produtores de petróleo e países densamente povoados. Detectaram que em nível agregado crescimento Granger causa poupança, mas poupança não Granger causa crescimento.

O trabalho de Attanasio et alii (2000), seguindo a metodologia de Carroll e Weil (1994), estendeu a amostra para 150 países, no período 1960-1995. Attanasio et alii (2000) analisaram as três variáveis no curto e no longo prazo, detectando que a taxa de poupança alta é positivamente relacionada com investimento; taxa de investimento Granger causa taxa de crescimento com um sinal negativo; e, taxa de crescimento Granger causa investimento com um sinal positivo.

Com relação aos estudos para poupança e crescimento na América Latina, destacamos Cardoso (1992). Aquela autora estuda a relação entre investimento, crescimento, taxa de câmbio real e termo de troca no período 1970-1985 para a Argentina, Brasil, Chile, Colômbia, México e Venezuela. Cardoso (1992) desenvolveu um modelo econométrico no qual concluiu que a participação do investimento público no PIB e os termos de troca explicam $74 \%$ da variação da participação do investimento privado no PIB.

Já Loayza et alii (2004), ao utilizarem a metodologia de Carrol e Weil (1994), encontraram resultados compatíveis com Carrol e Weil (1994) e de Attanásio (2000): crescimento Granger causa poupança, com uma forte evidência de que altas taxas de crescimento proporcionam altas taxas de poupança.

2 Austrália, Áustria, Bélgica, Canadá, Coréia do Sul, Dinamarca, Espanha, Estados Unidos, Finlândia, França, Grécia, Islândia, Irlanda, Itália, Japão, México, Holanda, Nova Zelândia, Noruega, Portugal, Reino Unido, Suécia, Suíça e Turquia. 


\section{Análise de Resultados}

As tabelas 1A, 1B e 1C (ver anexo) trazem as estatísticas descritivas das variáveis estudadas or país: crescimento real do PIB, poupança e investimento (formação bruta de capital fixo), em valores individuais por países.

$\mathrm{Na}$ variável crescimento, o destaque vai para o Chile e República Dominicana, nações que apresentam as maiores médias de crescimento no período, enquanto a Nicarágua apresenta a menor média de crescimento no período. O Brasil ocupa a nona posição em crescimento médio. Os países que apresentam os maiores percentuais médios de poupança em relação ao PIB são a Venezuela, com $26,29 \%$, e o Panamá, com $24,2 \%$. Os países com menores percentuais médio de poupança em relação ao PIB são a Nicarágua, com 4,65\%, e a Guatemala, com 11,76\%. O Brasil posiciona-se intermediariamente em relação aos demais países, na oitava posição.

Os maiores percentuais do PIB de investimento no período são observados para as seguintes nações: Nicarágua, com 23,84\%, e Honduras, com 22,84\%. Os menores desempenhos são: República Dominicana, com 14,85\%, e Equador, com 15,03\%. O Brasil posicionou-se na décima posição.

A tabela 2 sumariza o resultado dos testes Levin, Lin e Chu (2002) (LCC) e de Im, Peasaran e Shin (2003) (IPS). O teste LLC mostrou que as três variáveis (crescimento, investimento e poupança) são estacionárias ao nível de significância de 5\% ao redor de uma tendência determinística, ou seja, não possuem raiz unitária. Tais resultados foram confirmados pelo teste IPS.

Tabela 1 - Testes de Raízes Unitárias em painel

\begin{tabular}{ccccc}
\hline Variáveis & Teste & Estatísticas & P-value & Resultado \\
\hline Crescimento & LLC & 4,8907 & 0,0000 & $\mathrm{I}(0)$ \\
Crescimento & IPS & 5,2061 & 0,0000 & $\mathrm{I}(0)$ \\
Poupança & LLC & 3,6624 & 0,0001 & $\mathrm{I}(0)$ \\
Poupança & IPS & 3,3697 & 0,0004 & $\mathrm{I}(0)$ \\
Investimento & LLC & 3,3624 & 0,0004 & $\mathrm{I}(0)$ \\
Investimento & IPS & 2,8950 & 0,0019 & $\mathrm{I}(0)$ \\
\hline
\end{tabular}

Fonte: Elaboração própria a partir de dados do Banco Mundial

Alguns autores optam pelo modelo de efeitos fixos para a análise de causalidade em painel por considerá-lo mais adequado, como fez Attanasio et alii (2000). Em nossa análise, aplicamos o teste de Hausman, que é um critério de seleção adotado para selecionar o modelo adequado.

O resultado do teste Hausman, conforme tabela 15, aponta para a rejeição da hipótese nula de que o modelo mais adequado é o modelo de efeitos fixos a um nível de significância de 5\%. Nesse caso, não se pode rejeitar a hipótese alternativa de que o modelo mais adequado é o modelo com efeitos aleatórios. 
Tabela 2 - Resultados do teste de especificação de Hausman

\begin{tabular}{|c|c|c|c|c|}
\hline \multicolumn{5}{|c|}{ Coeficientes } \\
\hline & (b) & (B) & $(b-B)$ & $\operatorname{sqrt}\left(\operatorname{diag}\left(\mathrm{V} \_b-\mathrm{V} \_\mathrm{B}\right)\right)$ \\
\hline & fixo & & Diferença & S.E. \\
\hline invest & .2567083 & .2052726 & .0514356 & .0250907 \\
\hline saving & .0659069 & .0605789 & .005328 & .0147022 \\
\hline \multicolumn{5}{|c|}{ chi2 $(2)=(b-B)^{\prime}\left[\left(\mathrm{V} \_b-V \_B\right)^{\wedge}(-1)\right](b-B)=4.37$} \\
\hline \multicolumn{5}{|c|}{ Prob $>\operatorname{chi} 2=0.1126$} \\
\hline
\end{tabular}

Fonte: Elaboração própria

O teste de causalidade foi executando utilizando o modelo de efeitos aleatórios, conforme critério de seleção a partir o teste de Hausman. O método de estimação utilizado foi GMM,com variável defasada como instrumentos. Seguindo os trabalhos de Attanasio et alii (2000) e Loaysa (2004), utilizamos como instrumento a variável em diferença com quatro defasagens. Para comparar os resultados, utilizamos ainda o método de estimação OLS, e rodamos os modelos com a amostra disposta de duas maneiras: dados anuais e dados em médias qüinqüenais.

A tabela 4 reporta o resultado do teste de causalidade utilizando o painel com dados anuais. Todas as equações foram significantes a um nível de significância de $1 \%$, indicando uma ralação de causalidade de Granger bidirecional entre as três variáveis: poupança, investimento e crescimento. Os resultados foram significantes utilizando o método de estimação GMM e OLS, não havendo disparidade na direção da causalidade, nem quanto ao sinal. A relação de causalidade é positiva para as três situações analisadas. No entanto, os coeficientes das variáveis são maiores no método de estimação OLS em relação ao GMM, também nas três situações.

Tabela 3 - Teste de causalidade de Granger nas séries crescimento, investimento e poupança

\begin{tabular}{|c|c|c|c|c|}
\hline Efeito & Modelo OLS & Causalidade & Modelo GMM & Causalidade \\
\hline $\begin{array}{l}\text { Poupança } \\
\text { no Crescimento }\end{array}$ & $\begin{array}{c}0.757 * * * \\
(27.14)\end{array}$ & Sim & $\begin{array}{c}0.578 * * * \\
(16.28)\end{array}$ & Sim \\
\hline $\begin{array}{l}\text { Crescimento } \\
\text { na poupança }\end{array}$ & $\begin{array}{l}0.785 * * * \\
(29.17)\end{array}$ & Sim & $\begin{array}{c}0.564 * * * \\
(18.81)\end{array}$ & Sim \\
\hline $\begin{array}{l}\text { Poupança } \\
\text { no Investimento }\end{array}$ & $\begin{array}{c}0.807 * * * \\
(32.28)\end{array}$ & Sim & $\begin{array}{c}0.572 * * * \\
(19.10)\end{array}$ & Sim \\
\hline $\begin{array}{l}\text { Investimento } \\
\text { na poupança }\end{array}$ & $\begin{array}{c}0.812 * * * \\
(31.69)\end{array}$ & Sim & $\begin{array}{c}0.702 * * * \\
(23.63)\end{array}$ & Sim \\
\hline $\begin{array}{l}\text { Crescimento } \\
\text { no Investimento }\end{array}$ & $\begin{array}{c}0.809 * * * \\
(32.61)\end{array}$ & Sim & $\begin{array}{c}0.447 * * \\
(17.43)\end{array}$ & Sim \\
\hline $\begin{array}{l}\text { Investimento } \\
\text { No Crescimento }\end{array}$ & $\begin{array}{c}0.743 * * * \\
(12.10)\end{array}$ & $\operatorname{Sim}$ & $\begin{array}{r}0.569 * * * \\
(14.26)\end{array}$ & $\operatorname{Sim}$ \\
\hline
\end{tabular}

Estatística t entre parênteses. $\quad * \star \mathrm{p}<0.05, * \star \star \mathrm{p}<0.01$.

Fonte: Elaboração própria 
As conclusões do teste de causalidade de Granger utilizando dados de painel para países da América Latina, em dados anuais, no período de 1980 a 2009, utilizando as séries de poupança, investimento e crescimento, são:

- Relação de bi-causalidade entre crescimento e poupança: crescimento Granger causa poupança, e poupança Granger causa crescimento;

- Relação de bi-causalidade entre poupança e investimento: Poupança Granger causa investimento e investimento Granger causa poupança;

- Relação de bi-causalidade entre crescimento e investimento: crescimento Granger causa investimento, e investimento Granger causa crescimento.

Os referidos resultados são coerentes com aqueles encontrados por Attanásio et alii (2000), quando utilizaram dados de países da OCDE e encontraram uma relação de bi-causalidade com sinal positivo entre poupança e investimento e a relação de causalidade positiva do crescimento para o investimento. Além disso, está coerente com o estudo de Loayza (2004), que utilizou uma amostra de 1960 a 2000 para países da América Latina e Caribe. O estudo mostrou uma relação de equilíbrio entre poupança e crescimento.

Seguimos a metodologia proposta por Carroll e Weill (1994) e reproduzida por Judson e Owen (1999) e Attanasio et alii (2000) para analisar as relações de longo prazo entre poupança e crescimento e poupança e investimento, mas com alguns ajustes. Em nossa análise incluímos testes de raízes unitárias e de quebras estruturai em painel. Aqueles autores optaram pelo modelo de efeitos fixos. Em nossa análise, optamos por modelo de efeitos aleatório a partir da realização do teste de Hausman a fim de selecionar o modelo mais adequado.

A relação de equilíbrio de longo prazo entre as séries que poderia ser testada a partir de teste específico de cointegração não foi realizada, já que os testes indicaram que o painel é estacionário. Assim, nos atemos à relação de equilíbrio de longo prazo, conforme metodologia proposta por Carroll e Weill (1994).

Judson e Owen (1999) discutem o tamanho da amostra de um painel para aplicar a metodologia de Carroll e Weil (1994). Aqueles autores estavam preocupados com o viés dos estimadores de Mínimos Quadrados Ordinários para amostras pequenas. Judson e Owen (1999) demonstraram através de simulações de Monte Carlos que amostras de dimensão T a partir de trinta podem ter estimadores significantes, isto é, de viés estatisticamente pequeno. Coincidentemente, o período da amostra do presente estudo é de trinta anos em dados anuais, conforme recomenda a literatura.

A tabela 5 traz o resultado do cálculo dos efeitos de longo prazo entre as variáveis: crescimento-poupança, crescimento-investimento e poupançainvestimento. Os resultados mostraram que há uma relação de equilíbrio de longo prazo entre as variáveis. Todos os coeficientes foram significantes ao nível de $1 \%$.

Ainda sobre a tabela 5, a relação mais forte e positiva é entre a taxa de crescimento e poupança. A soma dos coeficientes da taxa de crescimento sobre 
a poupança foi 0,27 . A segunda maior soma foi 0,22 , correspondente à relação investimento sobre o crescimento, e uma soma de coeficientes de 0,15 da taxa de poupança sobre o crescimento.

Os coeficientes das correlações de longo prazo das três variáveis reportadas, conforme tabela 5, confirmam a mesma relação de equilíbrio observada a partir do teste da soma dos coeficientes. Os efeitos de longo prazo apresentaram-se maiores do que o valor da soma dos coeficientes das defasagens das variáveis. Essa evidência de relação de equilíbrio entre as variáveis: poupança, investimento e crescimento, aparecem em muitos estudos empíricos, como Attanasio et alii (2000).

Tabela 4 - Poupança, Crescimento e Investimento - efeitos de longo prazo

\begin{tabular}{lcc}
\hline & Poupança & Crescimento \\
\hline Poupança coeffs. & - & $0.19478^{* * *}$ \\
$\begin{array}{l}\text { Sum } \\
\text { ( p-value) }\end{array}$ & - & $(4.70)$ \\
Long-run & - & $0,2419^{* * * *}$ \\
( p-value) & - & $(0.000)$ \\
& & \\
Crescimento coeffs. & $0.26684^{* * * *}$ & - \\
Sum & $(5.13)$ & - \\
(p-value) & $0,3640^{* * *}$ & - \\
Long-run & $(0.000)$ & - \\
(p-value) & Investimento & Poupança \\
\hline
\end{tabular}

Investimento coeffs.

Sum

( $p$-value)

Long-run

( $\mathrm{p}$-value)

$0,15154^{* * *}$

$(3,65)$

$0,1786^{* * *}$

$(0,000)$

Poupança coeffs.

\begin{tabular}{ll}
$\begin{array}{ll}\text { Sum } \\
\text { ( p-value) }\end{array}$ & $\begin{array}{l}0.13223^{* * * *} \\
(4.19) \\
\text { Long-run } \\
\text { ( p-value) }\end{array}$ \\
\hline & $\begin{array}{l}0,1524^{* * *} \\
(0.000)\end{array}$ \\
\hline Crescimento coeffs. & Investimento \\
Sum & \\
( p-value) & $0.22227^{* * *}$ \\
Long-run & $(7.35)$ \\
( p-value) & $0.2858^{* * *}$ \\
& $(0.000)$
\end{tabular}

Investimento coeffs.

Sum

$0.15^{* * *}$

( $p$-value)

Long-run

(2.90)

( $p$-value)

$0.1765^{* * *}$

(0.000)

$\begin{array}{lll}\mathrm{N} & 468 & 468\end{array}$

Estatistica t entre parênteses. ${ }^{*} \mathrm{p}<0.05,{ }^{* *} \mathrm{p}<0.01,{ }^{* * *} \mathrm{p}<0.001$

Fonte: Elaboração própria 


\section{Conclusão}

Os testes econométricos indicam que há relação de equilíbrio de longo prazo entre as séries de poupança, de investimento e de crescimento neste grupo de 18 países latino-americanos entre 1980 e 2009. Os testes de causalidade de Granger adequado para dados de painel nos levaram a concluir por uma relação de equilíbrio de curto prazo entre as três variáveis. A relação de causalidade de Granger foi bi-direcional entre a poupança-investimento, poupança-crescimento e crescimento-investimento na América Latina. Esses resultados estão em sintonia com o estudo de Loaysa et alii (2004), que utilizaram dados da América Latina e Caribe, no período de 1960 a 2000. Logo, é possível concluir que existe uma relação de equilíbrio de curto e de longo prazo entre estas variáveis neste grupo de países neste período.

Outros estudos poderiam focar na mobilidade de capitais dentro do continente, procurando investigar o nível de abertura das economias, buscando confirmar tais indícios de baixa mobilidade de capitais dentro do continente.

\section{Referências}

Attanasio, Orazio P.; Picci, Lucio; Scorcu, Antonello E. (2000). "Saving, Growth, and Investment: a Macroeconomic Analysis Uing a Panel of Countries". The Review of Economics and Statistics, v. 82, n. 2, p. 182-211.

Besanger, S. (2004). "Optimal saving in a small open economy: the impact of labour, consumption, and the demographic Structure". Revue management et avenir, v. 1, n. 1 , p. $137-154$.

Boyce, John R. (2008).Savings and Growth in a Small Open Exhaustible Resource Economy. University of Calgary, Alberta, Canada.

Cardoso, Eliana. (1992). "O Investimento Privado na América Latina”. Revista de Economia Politica, v. 12, n. 4, p. 73-88.

Carroll, Christopher D.; Weill, David N. (1994). Saving and Growth: A Reinterpretation. Carnegie-Rochester Conference Series on Public Policy, v. 40, p. 133-194.

Feldstein, Martin. (1983). "Domestic Saving and International Capital Movement in the Long Run and the Short Run”. European Economic Review, v. 21, p. 129-151.

Feldstein, Martin; Horioka, Charles. (1980). "Domestic Saving and International Capital Flows". The Economic Journal, v. 90, n. 358, p. 314-329.

Finn, Mary G. (1990). "On Saving and Investment Dynamics a Small Open Economy”. Journal of International Economics, v. 29, p. 1-21.

Fouquau, J., Hurlin, C.; Rabaud, I. (2009). "The Feldstein-Horioka puzzle: A panel smooth transition regression approach". Economic Modeling, v. 25, p. 284-299.

Gunji, Hiroshi. (2003). "The Feldstein-Horioka puzzle and law”. Economics Bulletin, v. 11, n. 1, p. $1-12$. 
Im, K. S.; Pesaran, M. H.; Shin, Y. (2003). "Testing for unit root in heterogeneous panels". Journal of Econometrics, v. 115, p. 53-74.

Judson, Ruth A.; Owen, Ann L. (1999). "Estimating Dynamic Panel Data Models: A Guide for Macroeconomists". Economics Letters, v. 65, Issue 1, p. 9-15.

Kim, Sunghyun H. (2001). "The saving-investment correlation puzzle is still a puzzle". Journal of International Money and Finance, v. 20, Issue 7, p. 10171034.

Levin, A.; Lin, C.; Chu, J. (2002). "Unit root tests in panel data: asymptotic and finite-sample properties". Journal of Econometrics, n. 108, p. 1-24.

Levy, Daniel. (1995). "Investment-Saving Comovement under Endogenous Fiscal Policy”. Open Economies Review, n. 6, p. 237-254.

Levy, Daniel. (1998). Is the Feldstein-Horioka Puzzle Really a Puzzle? Emory University- Department of Economics, Atlanta, Working Paper.

Levy, Daniel. (2000)."Investment - Saving Comovement and Capital Mobility: Evidence from Century Long U.S. Time Series”. Review of Economic Dynamics, n. 3, p. 100-136.

Loayza, Norman; Fajnzylber, Pablo; Calderon, César. (2004). Economic Growth in Latin America and the Caribbean: Stylized Facts, Explanations, and Forecasts. Central Bank of Chile, Working Paper n. 256.

Mansoorian, Arman; Michelis, Leo; Mohsin, Mohammed. (2010). "Saving, Investment, Employment, and Inflation in a Small Open Economy with Habit Persistence". Macroeconomic Dynamics, v. 14, p. 365-387.

Mendonza, Enrique G. (1991). "Real Business Cycles in a Small Open Economy". The American Economic Review, v. 81, n. 4, p. 797-818. 